\title{
PENILAIAN PERTUMBUHAN DAN PERKEMBANGAN BALITA DENGAN MENGGUNAKAN KPSP DI PAUD WIJAYA KUSUMA PAPAHAN TASIKMADU KARANGANYAR
}

\author{
Ana Wigunantiningsih ${ }^{1}$, Luluk Nur Fakhidah ${ }^{2}$ \\ ${ }^{1,2}$ Prodi D3 Kebidanan, STIKes Mitra Husada Karanganyar: \\ Papahan, Tasikmadu, Karanganyar, Telp. (0271) 494581 \\ Email: wigunaana@gmail.com ${ }^{1,} \underline{\text { lu2nfh@gmail.com }}{ }^{2}$
}

\begin{abstract}
Abstrak
Tujuan kegiatan ini adalah untuk mengetahui status pertumbuhan dan status gizi anak dan melakukan klasifikasi perkembangan pada siswa PAUD Wijaya Kusuma Papahan Tasikmadu Karanganyar. Target Luaran dari kegiatan ini adalah semua siswa dapat mengikuti kegiatan dan dilakukan pemeriksaan tumbang serta orang tua bersedia untuk mengisi lembar observasi tumbang dan menyerahkan tepat waktu sehingga data mengenai tumbang dapat diambil kesimpulan dan klasifikasi proses tumbang apakah kategori normal, atau keterlambatan. Hasil dari program kegiatan pengabdian masyarakat ini diperoleh 17 siswa yang mengikuti pemeriksaan 100\% termasuk dalam status gizi baik, 16 siswa (94\%) memiliki tingkat perkembangan sesuai usia, 1 siswa (6\%) belum sesuai usia.
\end{abstract}

Kata kunci : Tumbang, Balita, KPSP

\section{PENDAHULUAN}

Tumbuh kembang adalah proses yang kontinue sejak dari konsepsi sampai dewasa, yang dipengaruhi oleh faktor lingkungan dan bawaan. Perkembangan (development) adalah perubahan secara berangsur-angsur dan bertambah sempurnanya fungsi alat tubuh, meningkatkan dan meluasnya kapasitas seseorang melalui pertumbuhan, kematangan atau kedewasaan (maturation), dan pembelajaran (learning).Perkembangan manusia berjalan secara progresif, sistematis dan berkesinambungan dengan perkembangan di waktu yang lalu. Perkembangan terjadi perubahan dalam bentuk dan fungsi kematangan organ mulai dari aspek fisik, intelektual, dan emosional. Perkembangan secara fisik yang terjadi adalah dengan bertambah sempurnanya fungsi organ. Perkembangan intelektual ditunjukan dengan kemampuan secara simbol maupun abstrak seperti berbicara, bermain, berhitung. Perkembangan emosional dapat dilihat dari perilaku sosial lingkungan anak. ${ }^{1,2}$

Tumbang harus selalu dipantau melalui deteksi dini secara rutin dan teratur agar tidak terlambat dalam penanganan jika ditemukan adanya masalah dalam tumbuh kembangnya. Deteksi tumbuh kembang adalah upaya yang dilakukan untuk menentukan penyimpangan tumbuh kembang anak sedini mungkin. ${ }^{3}$ Deteksi dini tumbang dapat dilakukan dengan penilaian penyimpangan pertumbuhan, perkembangan dan mental emosional. ${ }^{2}$

Penilaian perkembangan dilakukan dengan menggunakan Formulir KPSP yaitu alat/instrumen yang digunakan untuk mengetahui perkembangan anak normal atau ada penyimpangan. deteksi dini dilakukan pada balita dan anak pra sekolah. Fenomena yang ada di masyarakat kegiatan deteksi dini masih belum dilakukan secara rutin.

Oleh karena itu pada kesempatan ini ini sebagai wujud nyata pelaksanaan Tri Dharma Perguruan Tinggi Pengabdian Masyarakat dosen STIKes Mitra Husada akan mengadakan kegiatan "Penilaian Pertumbuhan dan Perkembangan Balita dengan Menggunakan KPSP di PAUD Wijaya Kusuma Papahan, Tasikmadu, Karanganyar" 


\section{METODE}

Berdasarkan studi pendahuluan yang dilakukan dengan survey ke PAUD Wijaya Kusuma Papahan penilaian tumbang pada balita belum dilakukan secara rutin. Biasanya penilaian tumbang dilaksanakan bersamaan dengan pelaksanaan kegiatan kelas. Para orang tua belum memahami tentang tumbang, hal ini dibuktikan dengan masih terbatasnya ibu yang menggunakan Kartu Kembang Anak (KKA) sebagai alat untuk melakukan deteksi dini tumbang bagi putera puterinya. Padahal kegiatan ini penting dilakukan agar dapat mengetahui secara dini adanya penyimpangan dalam pertumbuhan perkembangan anak dan melakukan tindak lanjut segera jika diperlukan. Kegiatan ini dilakukan dalam beberapa tahap yaitu tahap pertama pemeriksaan TB dan BB untuk menentukan status gizi, tahap kedua pemeriksaan LK dan tahap ketiga pemeriksaan perkembangan dengan formulir KPSP dilanjutkan dengan analisa.

\section{HASIL DAN PEMBAHASAN}

Kegiatan pengabdian msyarakat ini telah dilakukan pada tanggal 28 Desember 2016 dan 3 Februari 2017. Pelaksanaan kegiatan pertama dilakukan dengan mengukur BB, TB kemudian mengklasifikasikan status gizi anak. Kegiatan diikuti oleh 16 siswa (80\%) dari total 20 siswa.

Tabel 1. Hasil Pengukuran BB, TB dan Kategori status Gizi

\begin{tabular}{|l|l|l|l|l|l|l|}
\hline No & Nama & $\begin{array}{l}\text { Usia } \\
(\mathbf{d l m} \\
\text { bulan })\end{array}$ & BB & TB & IMT & Status Gizi \\
\hline 1 & An.S & 75 & 18 & 108 & 15,4 & Normal \\
\hline 2 & An.N & 76 & 25 & 122 & 16,8 & Normal \\
\hline 3 & An.V & 49 & 15 & 106 & 13,3 & Normal \\
\hline 4 & An.K & 68 & 21 & 116 & 15,6 & Normal \\
\hline 5 & An.L & 76 & 17 & 114 & 13,1 & Normal \\
\hline 6 & An.M & 74 & 23 & 119 & 16,2 & Normal \\
\hline 7 & An.Q & 70 & 15 & 103 & 14,1 & Normal \\
\hline 8 & An.A & 46 & & & 0,0 & Tidak Hadir \\
\hline 9 & An.N & 62 & 13 & 99 & 13,3 & Normal \\
\hline 10 & An.Ar & 49 & 14 & 100 & 14,0 & Normal \\
\hline 11 & An.Al & 70 & 19 & 109 & 16,0 & Normal \\
\hline 12 & An.H & 76 & 21 & 117 & 15,3 & Normal \\
\hline 13 & An.I & 69 & 15 & 111 & 12,2 & Normal \\
\hline 14 & An.V & 64 & 19 & 111 & 15,4 & Normal \\
\hline 15 & An.D & 57 & 15 & 102 & 14,4 & Normal \\
\hline 16 & An.N & 54 & 13,5 & 99 & 13,8 & Normal \\
\hline 17 & An.R & 45 & & & 0,0 & Tidak Hadir \\
\hline 18 & An.An & 59 & 15,5 & 100 & 15,5 & Normal \\
\hline 19 & An.Ab & 62 & & & 0,0 & Tidak Hadir \\
\hline 20 & An.Am & 52 & & & 0,0 & Tidak Hadir \\
\hline
\end{tabular}

Berdasarkan Tabel 1 diketahui bahwa 100\% siswa yang mengikuti kegiatan memiliki ukuran IMT> $>12 \mathrm{~cm}$ termasuk dalam kategori status gizi baik.

Status gizi merupakan keadaan kesehatan individu kelompok yang ditentukan oleh derajat kebutuhan fisik akan energy idan zat-zat gizi lain yangd iperoleh dari makanan yang dampak fisiknya diukur secaraa ntropometri. Di Indonesia cara yang paling umum dan sering digunakan adalah penilaian status secara antropemetri dengan menggunakan. indikator antropometri yang umum antara lain berat badan menurut umur $(\mathrm{BB} / \mathrm{U})$, tinggi badan 
menurut umur $(\mathrm{TB} / \mathrm{U})$, berat badan menurut tinggi badan $(\mathrm{BB} / \mathrm{TB})$, lingkar lengan atas menurut umur. ${ }^{4.56}$

Pengukuran Antropomerti BB/TB disebut dengan IMT (Indeks Masa Tubuh). Nilai IMT yang sudah didapatkan harus dibandingkan dengan Z-skor atau persentil. Hasil pengukuran terhadap 16 siswa PAUD Wijaya Kusuma didapatkan hasil semua siswa memiliki nilai IMT > 12, sehingga dapat disimpulkan bahwa status Gizi siswa PAUD Wijaya Kusuma Normal. Hal ini sesuai dengan klasifikasi IMT menurut WHO (1995) bahwa status gizi normal memiliki nilai $\mathrm{Z}$ antara $-2 \leq \mathrm{Z}$-skor $>+2$. $5,6,7$

Kegiatan kedua yang dilakukan adalah melakukan pengukuran LK (Lingkar Kepala) anak, didapatkan hasil sebagai berikut:

Tabel 2. Hasil Pengukuran Lingkar Kepala

\begin{tabular}{|l|l|l|l|l|}
\hline No & Nama & $\begin{array}{l}\text { Usia } \\
(\mathbf{d l m} \\
\text { bulan })\end{array}$ & LK & Status Gizi \\
\hline 1 & An.S & 75 & $\mathbf{5 0}$ & Normal \\
\hline 2 & An.N & 76 & $\mathbf{5 1}$ & Normal \\
\hline 3 & An.V & 49 & $\mathbf{4 5}$ & Normal \\
\hline 4 & An.K & 68 & $\mathbf{5 0}$ & Normal \\
\hline 5 & An.L & 76 & $\mathbf{5 0}$ & Normal \\
\hline 6 & An.M & 74 & $\mathbf{5 2}$ & Normal \\
\hline 7 & An.Q & 70 & $\mathbf{4 9}$ & Normal \\
\hline 8 & An.A & 46 & $\mathbf{-}$ & Tidak Hadir \\
\hline 9 & An.N & 62 & $\mathbf{4 5}$ & Normal \\
\hline 10 & An.Ar & 49 & $\mathbf{5 1}$ & Normal \\
\hline 11 & An.Al & 70 & $\mathbf{4 9}$ & Normal \\
\hline 12 & An.H & 76 & $\mathbf{5 2}$ & Normal \\
\hline 13 & An.I & 69 & $\mathbf{4 9}$ & Normal \\
\hline 14 & An.V & 64 & $\mathbf{5 0}$ & Normal \\
\hline 15 & An.D & 57 & $\mathbf{4 7}$ & Normal \\
\hline 16 & An.N & 54 & $\mathbf{4 5}$ & Normal \\
\hline 17 & An.R & 45 & $\mathbf{-}$ & Tidak Hadir \\
\hline 18 & An.An & 59 & $\mathbf{4 9}$ & Normal \\
\hline 19 & An.Ab & 62 & $\mathbf{-}$ & Tidak Hadir \\
\hline 20 & An.Am & 52 & - & Tidak Hadir \\
\hline
\end{tabular}

Pengukuran Lingkar Kepala (LK) penting dilakukan untuk mengetahui apakah berada dibawah atau diatas ukuran normal, ukuran ini bisa untuk mengetahui ada tidaknya masalah pada bayi atau anak. Secara normal, pertambahan ukuran lingkar pada setiap tahap relatif konstan dan tidak dipengaruhi oleh faktor ras, bangsa dan letak geografis. Jadwal pemantauan lingkar kepala anak disesuaikan dengan umurnya, Lingkar kepala diukur setiap bulan pada tahun pertama, setiap 3 bulan pada tahun ke dua, dan setiap 6 bulan pada usia 3 sampai 5 tahun.Saat lahir, ukuran lingkar kepala normalnya adalah 34-35 cm, lebih besar dari lingkar dada.Lingkar kepala akan bertambah $2 \mathrm{~cm}$ setiap bulan pada usia 0-3 bulan. Pada usia 4-6 bulan akan bertambah $1 \mathrm{~cm}$ per bulan, dan pada usia 6-12 bulan pertambahannya $0,5 \mathrm{~cm}$ per bulan. Sampai usia 5 tahun biasanya sekitar $50 \mathrm{~cm}$. Usia 5-12 tahun hanya naik sampai 52-53 $\mathrm{cm}$ dan setelah usia 12 tahun akan menetap serta tidak membesar lagi. ${ }^{18,9}$

Dari 16 siswa PAUD yang dilakukan pengukuran tidak didapatkan ukuran LK <44. Sehingga tidak ada hasil yang mengindikasikan adanya masalah terhadap anak. Pengukuran ini masih dalam kategori normal tetapi memiliki beberapa kekurangan diantaranya tidak dikaji LK anak pada saat lahir dan tidak dilakukannya perbandingan dengan nilai persentil. Jika ukuran LK lebih kecil -2 SD disebut sebagai mikrocepali jika +2 SD disebut makrosefali. 
Kegiatan ke tiga yaitu menilai perkembangan anak dengan menggunakan formulir KPSP (Kuesioner Pra Skrining Perkembangan). Pemantauan perkembangan dengan formulir KPSP disesuaikan dengan usia anak. Pemantauan perkembangan dengan formulir KPSP disesuaikan dengan usia anak. KPSP merupakan kuesioner skrining pendahuluan untuk anak usia 3 bulan sampai 6 tahun. Terdapat 10 pertanyaan dalam setiap kuesioner mengenai perkmebangan yang harus diisi dan dijawab. Pemeriksaan KPSP bisa dilakukan sendiri oleh pemeriksa dan bekerjasama (ditanyakan) kepada orang tua. Jika jawaban ya berjumlah 6 atau kurang dicurigai anak mengalami gangguan perkembangan sehingga perlu dirujuk untuk pemeriksaan lebih lanjut, dan jika jawaban Ya berjumlah 7 atau 8 perkembangan anak termasuk kategori meragukan (M). ${ }^{2,10}$

Dari 16 siswa yang dilakukan penilaian tumbang dengan kuesioner KPSP didapatkan 15 anak dengan hasil perkembangan sesuai dengan usia anak (S)dalam semua aspek yaitu aspek motorik, kasar, motorik halus, perkembangan bahasa dan bicara, personal sosial dan kemandirian, dan 1 anak hasil perkembangan meragukan (M). Hal ini karena hanya 7 pertanyaan dalam KPSP yang mendapatkan jawaban "Ya". Perkembangan anak yang belum berkembang adalah sosialisasi dan kemandirian yang terdapat pada pertanyaan nomor 2,3,6. Berdasarkan hasil $\mathrm{M}$ pada anak tersebut orang tua perlu untuk melakukan stimulasi perkembangan, lakukan pemeriksaan ulang 2 minggu kemudian dengan daftar pertanyaan yang sesuai usia anak. ${ }^{2,11}$

Meskipun penggunaan KPSP tidak dapat sepenuhnya digunakan untuk mendeteksi adanya kelainan perkembangan anak, akan tetapi cukup untuk bisa melakukan deteksi dini sehingga jika ditemukan hasil yang meragukan atau tidak sesuai dengan usia anak bisa segera dilakukan tindakan lebih lanjut berupa rujukan, pemeriksaan lebih lanjut ataupun konseling kepada orang tua tentang bagaimana melakukan stimulasi perkembangan yang sesuai dengan usia anak.

\section{KESIMPULAN}

Berdasarkan Hasil Kegiatan Pengabdian kepada masyarakat yang telah dilakukan di PAUD Wijaya Kususma Papahan Tasikmadu Karanganyar dapat disimpulkan bahwa 16 siswa yang mengikuti kegiatan termasuk dalam kategori status gizi baik dengan ukuran lingkar kepala normal dan berada pada tahap perkembangan yang normal sesuai dengan usia baik dari motorik kasar, motorik halus, bahasa maupun personal sosial dan kemandirian.

\section{SARAN}

Pemeriksaan deteksi dini tumbuh kembang anak sebaiknya dilakukan secara rutin oleh orang tua untuk mengantisipasi adanya gangguan pertumbuhan sehingga penanganan dapat dilakukan dengan tepat. Bagi penyelenggara PAUD diharapkan bisa menjalin kerjasama dengan tenaga kesehatan setempat untuk melakukan pemeriksaan tumbang secara rutin.

\section{UCAPAN TERIMA KASIH}

Kami mengucapkan terimakasih kepada LPPM STIKes Mitra Husada Karanganyar yang telah memberikan pendanaaan pelaksanaan kegiatan pengabdian kepada masyarakat bagi dosen. 


\section{DAFTAR PUSTAKA}

[1] Soetjiningsih, 2002, Tumbuh kembang Anak, Jakarta, EGC.

[2] Depkes RI dan IDAI, 2005, Pedoman Pelaksanaan Stimulasi, Deteksi dan Intervensi Dini Tumbuh Kembang Anak, Jakarta.

[3] Assyifa, 2016, Deteksi Dini Tumbuh Kembang, http://paudbfqnaskdb.blogspot.co.id/2016/05/penjelasan-ddtk-deteksi-dini-tumbuh.html, diakses tanggal 20 November 2016.

[4] Hermawan, A, 2006, Jaringan Syaraf Tiruan Teori dan Aplikasi, Jogjakarta, Penerbit ANDI.

[5] KemenKes RI, 2011, Keputusan Menteri Kesehatan Republik Indonesia tentang Standar Antropometri Penilaian Gizi Anak, Jakarta, Direktorat jenderal Bini Gizi dan Kesehatan Ibu dan Anak.

[6] Anggraeni dan Indrarti. 2010, Klasifikasi Status Gizi balita Berdasarkan Indeks Antropometri Menggunakan Jaringan Syaraf Tiruan, Jurnal SNASTI 2010 : ICCS-14.

[7] Riyadi, 2013, Mengukur Status Gizi dengan Indeks Masa Tumuh (IMT). https://hadiriyadi.blogspot.co.id/2013/01/mengukur-status-gizi-dengan-indeks.html, diakses tanggal 20 Maret 2017.

[8] Haryani, 2009, Keperawatan pediatrik: pengukuran Antropometri, http://keperawatanpediatrik.blogspot.com.

[9] Yolanda N dan Mangunatdmaja I, 2017, Pentingnya Pengukuran Lingkar Kepala dan Ubun-Ubun Besar, www.idai.or.id, diakses tanggal 17 Februari 2017.

[10] Soedjatmiko, 2001, Deteksi Dini Tumbuh Kembang Balita, Jurnal Sari Pediatri Vol 3, No 3 Desember 2001, Hal 175-188.

[11] Diana FM, 2010, Pemantauan Perkembangan Anak Balita, Jurnal Kesehatan Masyarakat Maret-September, 2010, Volume. 4, No. 2, Hal 116-129. 